\title{
Fabrication and Characterization of PVA-Gelatin-Nano Crystalline Cellulose based Biodegradable Film: Effect of Gamma Radiation
}

\author{
Nanda Karmaker ${ }^{1,2}$, Farhana Islam ${ }^{1}$, Md. Naimul Islam ${ }^{1}$, Md. Razzak ${ }^{1}$, Farjana A. Koly ${ }^{1}$, \\ A.M. Sararuddin Chowdhury ${ }^{2}$ and Ruhul A. Khan ${ }^{1, *}$ \\ ${ }^{1}$ Institute of Radiation and Polymer Technology, Bangladesh Atomic Energy Commission, Dhaka-1000, \\ Bangladesh \\ ${ }^{2}$ Department of Applied Chemistry and Chemical Engineering, University of Dhaka, Dhaka-1000, Bangladesh
}

\begin{abstract}
Poly Vinyl Alcohol (PVA) films were prepared using solution casting. The Tensile Strength (TS), Tensile Modulus (TM) and Elongation at break (Eb) of the prepared films were found to be $23.58 \mathrm{MPa}, 32 \mathrm{MPa}$ and $302 \%$ respectively. Moisture content and water uptake analysis were also checked. Then, gelatin and nano crystalline cellulose (NCC) were incorporated into PVA film and again physchio-mechanical properties were measured. The TS, TM and Eb values of PVA/Gelatin-based films were $23.57 \mathrm{MPa}, 114.58 \mathrm{MPa}, 48.10 \%$ respectively. On the other hand, PVA/Gelatin/NCC-based films showed the TS, TM, and Eb values of $32.92 \mathrm{MPa}, 129.8 \mathrm{MPa}, 58.5 \%$ respectively. Thermal degradation test was accomplished by Thermo-Gravimetric Analysis (TGA) and Differential Scanning Calorimetry (DSC). Spectroscopic analysis was also done by Fourier Transfer Infra-Red (FTIR). The soil degradation test confirmed the inherent biodegradable nature of the films. The prepared bio-polymeric films were exposed to gamma radiation. It was found that at $6 \mathrm{kGy}$ dose the mechanical properties of the films improved significantly.
\end{abstract}

Keywords: Polyvinyl Alcohol, Nano Crystalline Cellulose, Biodegradable, Gelatin, Gamma Radiation.

\section{INTRODUCTION}

Investigation is being carried out to design an ecofriendly packaging materials in place of petroleumbased synthetic polymers such as polyethylene (PE) and polypropylene (PP). Presently, synthetic polymers are widely used as packaging materials due to their excellent thermo-mechanical and barrier properties. Moreover, these synthetic polymeric materials are also low-priced. Synthetic polymers are non-biodegradable and a threat to the environment. It is high time to develop an alternative packaging films which are biodegradable in nature [1-2]. The biodegradable polymers which can replace the synthetic polymers include poly lactic acid, polycaprolactone, poly glycolic acid, chitosan, alginate, cellulosic materials. Bioactive packaging is an intelligent or smart system involving interactions between package or package components and food or internal gas atmosphere and complies with consumer demands for high quality, fresh-like, and safe products. It is the most favorable smart packaging systems for regulatory of spoilage and pathogenic micro-organisms. It is a ground-breaking approach to improve the condition of the packaging to extend shelflife or expand safety or sensory properties while preserving the quality of the food [3-4].

*Address correspondence to this author at the Institute of Radiation and Polymer Technology, Bangladesh Atomic Energy Commission, Dhaka-1000, Bangladesh; Tel: +8801618585111; Fax: +8827788189;

E-mail:dr.ruhul_khan@yahoo.com
Polyvinyl alcohol (PVA) is one of the most common water-soluble polymers produced on a huge scale commercially. PVA has great probability in various industrial applications, such as emulsifier, a stabilizer for colloid suspensions, adhesive. Because of its outstanding properties, such as good barrier property, high strength, good film-forming property and highly hydrophilic property, PVA has been used in the form of fibers, films, hydrogels, and glues. Because the melting point (Tm, typically $226{ }^{\circ} \mathrm{C}$ ) and the decomposition temperature of PVA are very close, the thermal degradation also undergoes simultaneously during melting [5-6]. PVA is a semicrystalline polymer in which high physical interactions between existing polymer chains, due to the hydrogen bonding between hydroxyl groups. Hydrogen bonding also controls the thermal properties of PVA. PVA is a reasonable polymer which owns desirable properties such as water solubility, biocompatibility, and biodegradability [7-8].

Gelatin is a dissimilar mixture of water-soluble proteins of high average molecular mass which are absent in nature but can be derived by the hydrolysis of collagen, a protein of mammal external protective tissues, by boiling skin, tendons, ligaments, bones, etc. with water. It absorbs 5-10times its weight of water to form a gel in solutions below $35-40^{\circ} \mathrm{C}$. Commercially gelatin is obtained as a colorless or slightly yellow, transparent, brittle, practically odorless, tasteless sheets, flakes, or coarse powder [9-10]. There are unbounded potentials for amending the properties of gelatin due to the presence of bi and poly functional 
organic and inorganic compounds that can interact with the particular gelatin functions is very large indeed. Chemical modifications, aiming at an increase in the degree of protein cross-linking varied upon the reactivity of the protein constituents, the specificity of the modifying agent, the amino acid composition, and the reactivity of amino acid and the tri-dimensional structure of the protein molecule. Generally, chemical reactivity of proteins depends on the side chain, the amino acid composition and the free amino and carboxyl groups. The most responsive protein groups are serine (primary-OH), hydroxiproline (secondary$\mathrm{OH}$ ), threonine (secondary-OH), tyrosine (phenolic$\mathrm{OH})$, aspartic acid $(-\mathrm{COOH})$, glutamic acid $(-\mathrm{COOH})$, lysine (-NH2) and arginine (-C(:NH).NH2). Crosslinking of gelatin macromolecules is acknowledged for increasing the viscosity of the gelatin solutions, strength and melting points of gelatin gels [11-12].

Nanocrystalline cellulose (NCC) is a stimulating nanomaterial for the construction of cheap, lightweight and very strong nanocomposites. NCC is found from native cellulose sources and composed of nanometersized rod like particles. The NCC used in this experiment is extracted from bleached softwood kraft pulp by controlled acid hydrolysis. Wood cellulose nanocrystals possesses cross-sectional dimensions of $6-7 \mathrm{~nm}$ and lengths ranging from 80 to $100 \mathrm{~nm}$. NCC is estimated to show high stiffness since the Young's (elastic) modulus along the axis of the cellulose nanocrystals is $137 \mathrm{GPa}$ or more. The tensile strength (TS) of the crystal structure was evaluated by modeling to be approximately $7.5-7.7 \mathrm{GPa}$. It is predicted that NCC nanocomposites may provide value-added materials with superior performance and extensive applications for the next generation biodegradable materials [13-14]. Cellulose nanocrystals are ordinary and have excellent reinforcing agent for thermoplastic polymers owing to their outstanding mechanical properties and large aspect ratio. Usually, dried NCC aggregates due to its small size, high surface energy, and strong intrinsic van der Waals forces [15-16].

Nowadays, there has been a continuous and rapid growth in the development and application of radiation techniques including gamma radiation. Gamma radiation is a type of ionizing radiation. Irradiation of polymers with high-energy gamma rays are responsible for the formation of very reactive intermediates in the forms of excited states, ions, and free radicals. These intermediates are almost spontaneously consumed in several reaction pathways which ultimately produce oxidize products, grafts, crosslinking, and scission of main or side chains (degradation). The relative extent of these alterations depend on the nature of the polymer and the treatment condition during and after irradiation, and close control of these factors makes possible the modification of polymers by radiation processing [17]. The several advantages of gamma radiation are continuous operation, minimum time requirement, less atmospheric pollution, and curing at ambient temperatures. Radiation induced processes also have many advantages other than conventional methods. Catalysts or additives are not required to initiate the reaction, as absorption of radiation energy by the polymer backbone generally initiates a free radical process. Moreover, the radiation dose rate can effortlessly control and make the reaction easier and precise. Finally, radiation processing is temperature liberated and is therefore a zero activation energy process is considered [18].

In this study, the purpose was to fabricate a biodegradable film using the PVA, Gelatin and NCC and observe the thermo-mechanical properties and changes due to radiation dose.

\section{MATERIALS AND METHODS}

\section{Materials}

PVA was purchased from MERCK-Germany, having molecular weight $145000 \mathrm{~g} / \mathrm{mol}$ and $99 \%$ hydrolyzation. The purified gelatin was obtained from MerckGermany. The Nano Crystalline Cellulose (NCC) was extracted from bleached softwood kraft pulp. The particle size was 8-12 $\mathrm{nm}$ and length had a range of 80-100 nm. Deionized water was collected from the laboratory of Institute of Radiation and Polymer Technology.

\section{Preparation of Biodegradable PVA-Based Films Using Solution Casting}

1gm of PVA crystals was weighed by electronic balance and taken into a petri dish. Then the measured PVA was taken and poured into $100 \mathrm{ml}$ hot deionized water. A magnetic stirrer was placed to ensure the homogeneous mixing of PVA. Then the lid of the beaker was sealed using a glass plate. The temperature was also checked with the interval of time to maintain the parameters. It took about 2 hour to dissolve the PVA completely. Then the warm solution was cast in a glass mold. After $24 \mathrm{hrs}$ at Relative Humidity $(\mathrm{RH}) 65 \%$ and temperature at $30^{\circ} \mathrm{C}$ the film was dried and then peeled off using a spatula and was stored in a desiccator containing blue silicon beads 
prior to characterization. Thus the control sample was prepared. After that, $1 \mathrm{gm}$ of gelatin was taken in different beaker and marked to $100 \mathrm{ml}$ by the freshly prepared base solution. Then the $10 \%$ NCC of the total weight was added to the PVA-Gelatin solution and mixed using Ultrasonicator. Finally the film was casted into the silicon paper covered glass mold and kept in desiccator for further characterizations.

\section{Evaluation of Mechanical Properties}

Tensile strength (MPa) and elongation at break (\%) of the films were examined by the Universal Testing Machine (Hounsfield series, model, INSTRON 1011, UK) with a crosshead speed of $10 \mathrm{~mm} / \mathrm{min}$. The experiment was carried out according to ASTM D 63801 . The size of the experimental sample were: $80 \mathrm{~mm}$ $\times 10 \mathrm{~mm}$.

\section{Determination of Thermal Properties}

Thermal properties of biopolymeric films were investigated by thermo gravimetric analysis (TGA). TGA was performed under nitrogen atmosphere from room temperature to $800^{\circ} \mathrm{C}$ at a rate of $10^{\circ} \mathrm{C} / \mathrm{min}$ with a TGA-50 instrument (Shimadzu Cooperation, Japan). The weight of the sample varied from 2 to $3 \mathrm{mg}$. the maximum temperature range for this instrument was from room temperature to $800^{\circ} \mathrm{C}$ and the cell was made of alumina. Thermal properties were evaluated using differential scanning calorimetry (DSC). DSC was performed using DSC-60 (Shimadzu Cooperation, Japan), under liquid nitrogen atmosphere and temperature ranges from room temperature to $400^{\circ} \mathrm{C}$. The heating rate was $10^{\circ} \mathrm{C} / \mathrm{min}$ and weight of sample varied from 2 to $3 \mathrm{mg}$.

\section{Characterization Using Spectroscopic Method}

A spectrum two spectrophotometer (Perkin-Elmer) equipped with an attenuated total reflectance (ATR) device and a high linearity lithium tantalite (HLLT) detector was used for recording the spectra. The device was used for analysis of solids. Spectrum 10TM software was used for spectral identification. Films were stored in a desiccator containing blue silica gel for 72 minutes at room temperature. The films were then placed on a zinc selenide crystal, and the analysis was performed within the spectral region of $650-4000 \mathrm{~cm}^{-1}$. After attenuation of total reflectance and baseline correction, spectra were normalized with a limit ordinate of 1.5 absorbance units.

\section{Assessment of Physical Properties}

Weighted test specimens were immersed into glass beakers containing $50 \mathrm{ml}$ of deionized water. The test was carried out for 30 minutes at $30^{\circ} \mathrm{C}$ temperature. After 30 minutes, samples were withdrawn from the beaker, wiped out properly for removing the surface moisture and then reweighed. Water uptake of the films was measured by a weight difference methodology. The equation for water uptake was as follows: Water uptake $(\%)=($ Wwet - Wdry $) /$ Wdry $\times 100$, where Wwet indicated the weight of the sample after immersion in water and Wdry represented the weight of the film before immersion. Moisture content analysis was done by using KERN-D85. It runs at $120^{\circ} \mathrm{C}$ and gives the moisture content result on percentage basis.

\section{Determination of Crystalline Properties}

Crystallinity of the samples were determined using the X-Ray Diffraction (XRD) process. The XRD spectra of NCC was analyzed by the Rigaku ULtima IV X-RAY diffractometer (Rigaku Americas Corporation, Japan). The ultima IV was equipped with unique and patented cross beam optics (CBO). The sample was cut into a square shape with the length of less than $1.5 \mathrm{~cm}$.

\section{Analysis of Surface Morphology}

Surface morphology of the samples were evaluated using Scanning Electron Microscopy (SEM). The SEM analysis was done using the machine purchased from JEOL, Japan. The samples were cut into shapes of $1 \mathrm{~cm} \times 1 \mathrm{~cm}$.

\section{Degradation Test of the Film}

The biodegradability test of the films in soil medium was investigated. For this purpose, sample biopolymeric films were weighed individually and buried in the garden soil for a period of 7 days. After that, samples were taken out from soil carefully and degradation of the samples was inspected visually.

\section{Irradiation Effect}

The PVA-Gelatin-NCC based biopolymeric films were taken in an air tight zipper poly bag. Then the films were exposed to gamma rays, generated from a Co-60 source in the Institute of Radiation and Polymer Technology, Atomic Energy Research Establishment, Savar, Dhaka. The doses of radiation were 6kGy. Prior to analysis, the samples were kept in a desiccator for 24hours. 


\section{RESULTS AND DISCUSSIONS}

\section{Physico-Mechanical Properties of the PVA-Based Biopolymeric Films}

Fabricated films of PVA, PVA-Gelatin and PVAGelatin-NCC were experimented about their physicomechanical properties before and after radiation dose. Significant changes were found which are illustrated into Tables 1 and 2.

Table 1 describes the mechanical properties and moisture content analysis of the four PVA-based Gelatin-NCC biopolymeric films. In this table, mechanical evaluation of the tensile strength (TS), tensile modulus (TM) and elongation at (Eb) are shown. Moisture content denotes the physical properties of the biodegradable films. From the data, we can clearly visualized the mechanical properties of PVA, PVA-Gelatin and PVA-Gelatin-NCC films. The TS, TM and Eb values of PVA film were found to be $23.58 \mathrm{MPa}, 32 \mathrm{MPa}$ and $302 \%$ respectively and for PVA-Gelatin film these values were found to be 26.2 $\mathrm{MPa}, 115.58 \mathrm{MPa}$ and $48.10 \%$ individually. With the incorporation of $10 \%$ NCC into PVA-Gelatin film the mechanical properties were increased significantly. The TS, TM and Eb values were obtained to be $32.92 \mathrm{MPa}$, $129.8 \mathrm{MPa}$ and $58.5 \%$ correspondingly. The outstanding properties were found for the incorporation of NCC can be explained from the structures of PVA, Gelatin and Cellulose. The presence of protein molecules in gelatin forms carbonyl groups, hydrogen bonds, nitryl bonds, etc. But, incorporation of NCC in PVA-Gelatin film increases the stiffness and and strength. The moisture contents of the films eg, PVA, PVA-Gelatin and PVA-Gelatin-NCC were found 21.3, 20 and $18.7 \%$ respectively.

The Table 2 demonstrates the physico-mechanical properties of the PVA, PVA-Gelatin and PVA-GelatinNCC-based biopolymeric films after the $6 \mathrm{kGy}$ radiation dose. Radiation dose significantly changed the TS, TM and $\mathrm{Eb}$ values of the films. After radiation the TS, TM Eb values of PVA films were $27 \mathrm{MPa}, 62.5 \mathrm{MPa}$ and $314.5 \%$, for PVA-Gelatin film those were denoted 29.32 $\mathrm{MPa}, 157.8 \mathrm{MPa}$ and $54.10 \%$ separately. Addition of NCC improved the mechanical properties drastically. The TS, TM and Eb values were found to be 40.38 $\mathrm{MPa}, 139.7 \mathrm{MPa}$ and $14.9 \%$ respectively. The moisture content percentage was found for PVA, PVA-Gelatin and PVA-Gelatin-NCC films were recorded $18 \%$, $19.8 \%$ and $14.9 \%$. After radiation the cross-linking was responsible for this drastic changes into mechanical properties. Water uptake test was carried out upto 30 minutes of the films before and after radiation. The water uptake percentages are showed in Table 3.

Table 3 illustrates the water uptake percentages of PVA, PVA-Gelatin and PVA-Gelatin-NCC-based biopolymeric films before radiation dose. The water uptake percentages of the films raised gradually then after a certain time the water uptake percentages reduced. With the immersion into deionized water the film tried to absorb water upto $100 \%$ and even higher. After reaching the peak level, the films started to dissolve into water and reduced its weight rapidly. Gelatin had better water barrier properties than PVA because of the presence of protein structures which

Table 1: Physico-Mechanical Properties of the PVA-Gelatin-NCC-Based Biopolymeric Non-Irradiated Films

\begin{tabular}{|c|c|c|c|c|c|}
\hline Sample No. & Sample Film & $\begin{array}{c}\text { Tensile Strength } \\
\text { (TS) (MPa) }\end{array}$ & $\begin{array}{c}\text { Tensile Modulus } \\
\text { (TM) (MPa) }\end{array}$ & $\begin{array}{c}\text { Elongation at break } \\
\text { (Eb) (\%) }\end{array}$ & $\begin{array}{c}\text { Moisture Content } \\
\text { (\%) }\end{array}$ \\
\hline \hline 1. & PVA & 23.58 & 32 & 302 & 21.3 \\
\hline 2. & PVA-Gelatin & 26.2 & 115.58 & 48.10 & 20 \\
\hline 3. & PVA-Gelatin-NCC & 32.92 & 129.8 & 58.5 & 18.7 \\
\hline
\end{tabular}

Table 2: Physico-Mechanical Properties of PVA, PVA-Gelatin and PVA-Gelatin-NCC-Based Biopolymeric Irradiated Films

\begin{tabular}{|c|c|c|c|c|c|}
\hline Sample No. & Sample Film & $\begin{array}{c}\text { Tensile Strength } \\
\text { (TS) (MPa) }\end{array}$ & $\begin{array}{c}\text { Tensile Modulus } \\
\text { (TM) (MPa) }\end{array}$ & $\begin{array}{c}\text { Elongation at break } \\
\text { (Eb) (\%) }\end{array}$ & $\begin{array}{c}\text { Moisture Content } \\
\text { (\%) }\end{array}$ \\
\hline \hline 1. & PVA & 27 & 62.5 & 314.5 & 18 \\
\hline 2. & PVA-Gelatin & 29.32 & 157.8 & 54.10 & 19.8 \\
\hline 3. & PVA-Gelatin-NCC & 40.38 & 139.7 & 62.8 & 14.9 \\
\hline
\end{tabular}


Table 3: Data of Water Uptake Percentages of PVA-Based Non-Irradiated Films

\begin{tabular}{|c|c|c|c|c|}
\hline Sample No & Soaking Time & PVA & PVA-Gelatin & PVA-Gelatin-NCC \\
\hline \hline 1. & 5 & 45 & 63 & 58 \\
\hline 2. & 10 & 85 & 85 & 76 \\
\hline 3. & 15 & 112 & 101 & 94 \\
\hline 4. & 20 & 98 & 119 & 90 \\
\hline 5. & 25 & 85 & 94 & 68 \\
\hline
\end{tabular}

Table 4: Data of Water Uptake Percentages of PVA-Based Irradiated Films

\begin{tabular}{|c|c|c|c|c|}
\hline Sample No & Soaking Time & PVA & PVA-Gelatin & PVA-Gelatin-NCC \\
\hline \hline 1. & 5 & 56 & 60 & 63 \\
\hline 2. & 10 & 84 & 88 & 75 \\
\hline 3. & 15 & 102 & 111 & 98 \\
\hline 4. & 20 & 95 & 120 & 91 \\
\hline 5. & 25 & 78 & 92 & 82 \\
\hline
\end{tabular}

helped to withstand more time while immersing into deionized water. Incorporation of NCC improved the surface morphology which helped to be more resistant to water.

The Table $\mathbf{4}$ describes the water uptake percentages of PVA, PVA-Gelatin and PVA-GelatinNCC-based biopolymeric films after irradiation. After irradiation, the water uptake percentages decreased significantly for the biopolymeric films. It is clearly visualized from the table that, after radiation the NCC based film showed the lowest water uptake properties. After gamma irradiation, the cross-linking among the PVA-Gelatin-NCC were rearranged. This rearrangements resulted into this lower water uptake percentages for all the films.

Thermal Properties of the PVA, PVA-Gelatin and PVA-Gealtin-NCC-Based Biopolymeric Films

Thermal properties were measured into two ways, one was thermo-gravimetric analysis and other was differential scanning calorimetry.

\section{Thermo-Gravimetric Analysis (TGA)}

The thermo-gravimetric analysis of the PVA, PVAGelatin and PVA-Gelatin-NCC based biopolymeric films was described in Figure 1.

From the graph we could get a clear view about the thermal decomposition of the films with the increase in the temperature. For all of the film, temperature within $100^{\circ} \mathrm{C}$ the unbound water, under $200^{\circ} \mathrm{C}$ the chemically bound water, other decomposition temperatures were evaluated for the breakage of bonds between PVA and biopolymers. At last, ash content was varied to 3-6 \% on average for the films. For PVA film, there was a decomposition at $348.52^{\circ} \mathrm{C}$ due to breakage of $\mathrm{C}-\mathrm{C}$ bond. The thermogram of PVA-Gelatin had a sharp decrease at $478.7^{\circ} \mathrm{C}$, which was mainly due to the cleavage of $\mathrm{C}=\mathrm{N}$ bond due to the presence of protein molecules in gelatin. NCC also had 2 steps decomposition. $1^{\text {st }}$ one was at $114.24^{\circ} \mathrm{C}$ and mass loss was $18.5 \%$. This occurred due to cleavage of hydroxyl

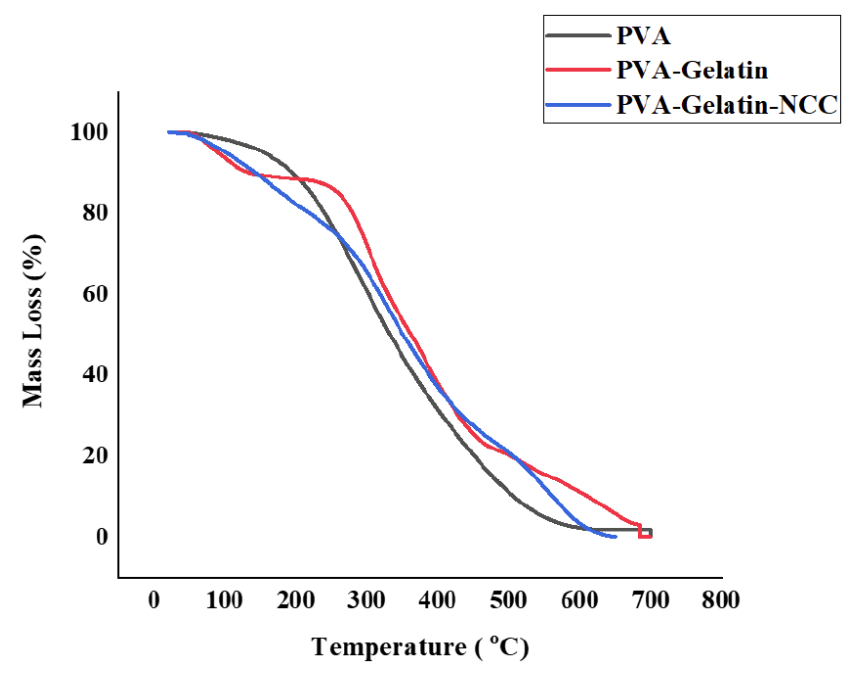

Figure 1: Graphical representation of thermo-gravimetric analysis for PVA, PVA-Gelatin and PVA-Gelatin-NCC films. 
groups in polysaccharides and water vaporization. Secondly the decomposition occurred around $678.25^{\circ} \mathrm{C}$ and mass loss is $85.51 \%$. This occurs due to the breakage of glycosidic bond and hydrogen bonds. It is noticed that TGA properties improved significantly with $10 \%$ NCC film and it could withstand about $800^{\circ} \mathrm{C}$ for fully decomposition.

\section{Differential Scanning Calorimetry (DSC)}

The thermal degradation of PVA, PVA-Gelatin and PVA-Gelatin-NCC-based biopolymeric films by differential scanning calorimetric method was illustrated in Figure 2.

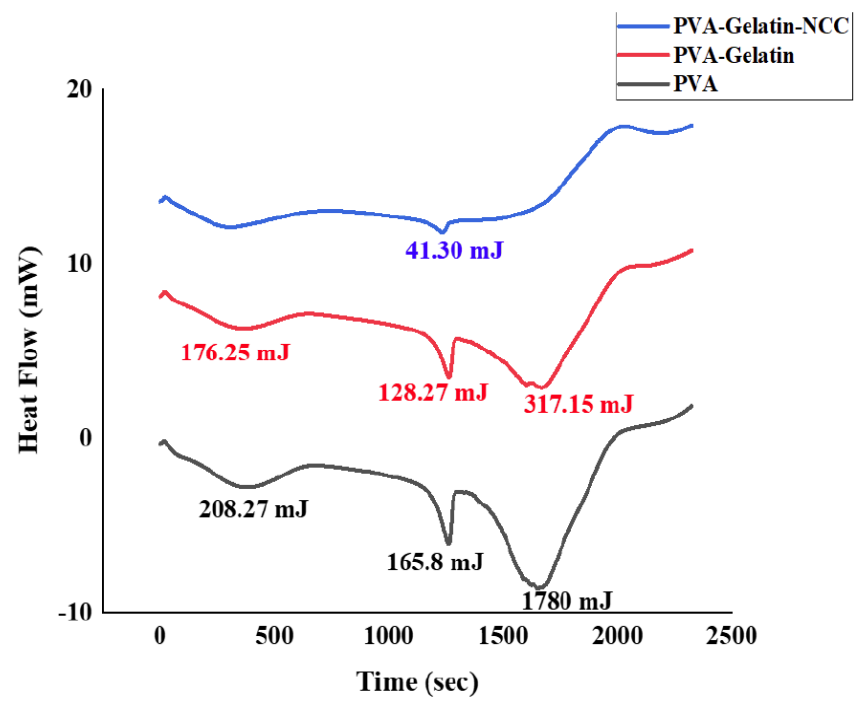

Figure 2: Graphical representation of differential scanning calorimetry for PVA, PVA-Gelatin and PVA-Gelatin-NCCbased biopolymeric films.

From the thermograms we got a view about the change of enthalpy of PVA due to presence of Gelatin and NCC. The heat of enthalpy for PVA film was found to be 168.86 mili joule at the glass transition $\left(T_{g}\right)$ of $227.70^{\circ} \mathrm{C}$. PVA-Gelatin film showed $\mathrm{T}_{\mathrm{g}}$ at $225.69^{\circ} \mathrm{C}$ with the change of enthalpy 124.26. On the other hand, PVA-Gelatin-NCC film had a heat enthalpy 119.64 mili joule at $226.08^{\circ} \mathrm{C}$. These DSC data indicated how the PVA and PVA-Gelatin films changed at glass-transition temperature with the incorporation of nano crystalline cellulose.

\section{Spectroscopic Analysis of PVA and PVA-Gelatin- NCC-Based Films}

Figure 3 demonstrated the Fourier Transform InfraRed Spectroscopic analysis of PVA, PVA-Gelatin and PVA-Gelatin-NCC based biopolymeric films.

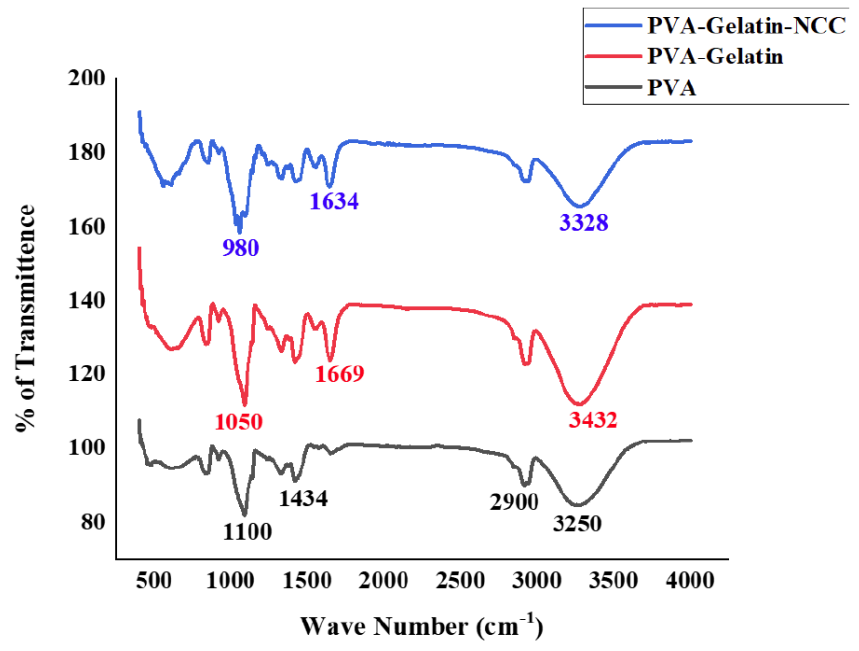

Figure 3: Graphical representation of Fourier Transform Infra-red Spectroscopy of PVA, PVA-Gelatin and PVAGelatin-NCC-based films.

The graph represented the functional groups present in the biopolymers due to vibration. The PVA sowed a characteristic peak at $1100 \mathrm{~cm}^{-1}$ for the functional carboxyl group present in PVA structure. The other to characteristic peaks were found at $2900 \mathrm{~cm}^{-1}$ for the $\mathrm{C}-\mathrm{H}$ stretching bond and at $3250 \mathrm{~cm}^{-1}$ for the O$\mathrm{H}$ bond due the Hydrogen bond present in PVA film. Specific peak was found at $1669 \mathrm{~cm}^{-1}$ for the PVAGelatin film which was characteristic of the $\mathrm{C}=\mathrm{N}$ bond between PVA and gelatin. For the NCC spectroscopy, a shape peak was obrtained at $980 \mathrm{~cm}^{-1}$ for the $\mathrm{C}-\mathrm{H}$ bond. The $\mathrm{C}-\mathrm{O}-\mathrm{C}$ asymmetric bands present at 1634 $\mathrm{cm}^{-1}$ and $\mathrm{O}-\mathrm{H}$ stretching vibration at $3328 \mathrm{~cm}^{-1}$ which were found in the spectrum. These could be obtained from the absorbed water molecule by the cellulose.

\section{Crystalline Properties of PVA-Gelatin-NCC-Based Films}

The typical X-ray diffraction patterns (XRD) of PVA, PVA-Gelatin and PVA-Gelatin-NCC-based biopolymeric film and their blend sample with NCC, at room temperature, in the scanning range $3^{\circ} \leq 2 \theta \leq 70^{\circ}$ were shown in Figure 4.

PVA shows crystalline peak at $2 \theta$ value of 19.85 . The sample was polymeric film, so most of the peak shows the amorphous nature. Gelatin is a protein based polymer and contains high amount of amines and amides groups. Mostly, it doesn't show that much crystalline properties. It shows little bit crystalline structure which is observed on $2 \theta$ value 19.12 . With the incorporation of NCC into the film the crystalline properties increased significantly. The crystalline peaks are available at $2 \theta$ value of 19.65 . These values are 
assigned to a mixture of (110), (200) and (201) respectively.

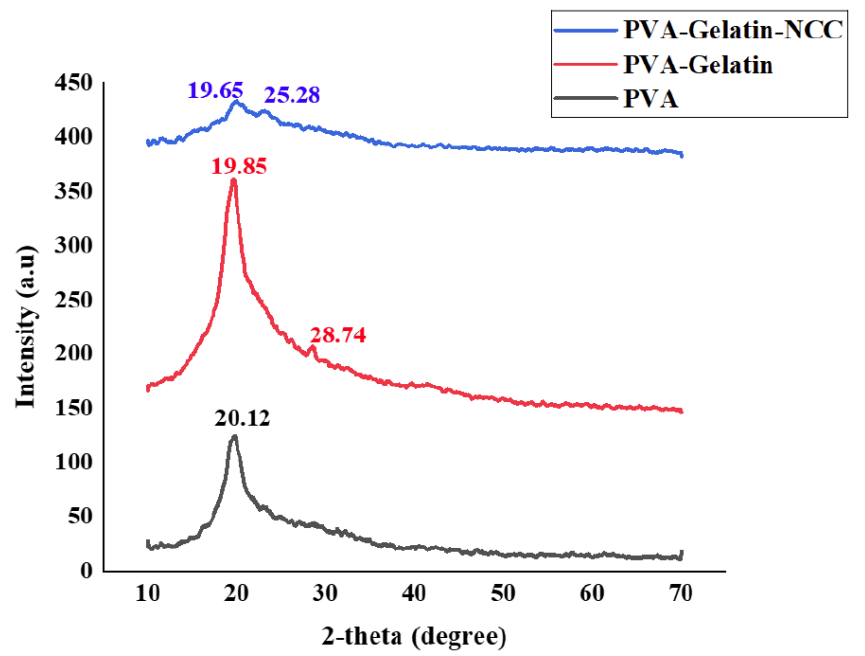

Figure 4: Graphical representation of X-Ray diffraction of PVA-Gelatin-NCC-based films.

\section{Surface Morphological Analysis of PVA-Gelatin- NCC-Based Films}

Figure 5 represented the surface morphology analysis images of PVA, PVA-Gelatin and PVAGelatin-NCC films.

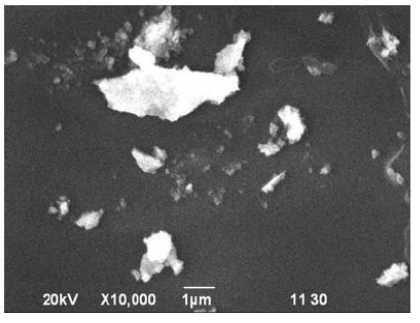

a

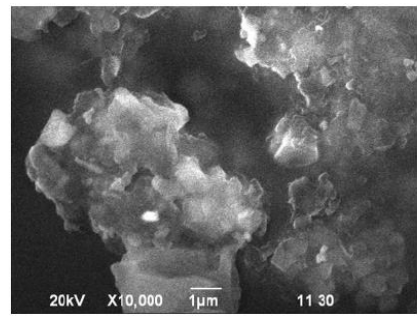

b

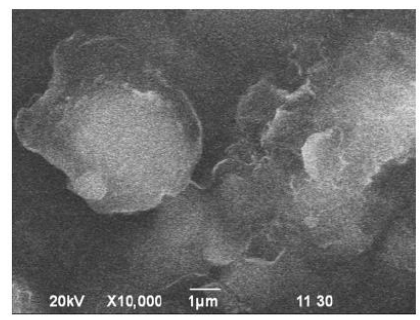

c

Figure 5: Scanning electron microscopic images of (a) PVA, (b) PVA-Gelatin and (c) PVA-Gelatin-NCC films.

The image (a) showed the homogeneous surface of PVA. From the image, the presence of moisture or any volatile particle was confirmed. In image (b) the heterogeneous nature was noticed due to mixing with gelatin. The third (c) image described the surface morphological changes due to addition of nano crystalline cellulose. Nano particle present in small amount changed the surface morphology with the existence of glycosidic bonds in cellulose structure.

\section{Biodegradability Tests of PVA-Gelatin-NCC Films}

The PVA, PVA-Gelatin and PVA-Gelatin-NCC films were cut into small strips and placed in soil media for 7 days. It was observed clearly that the films were attacked by microorganism present in soil. After 7 days, the films were again buried back to the soil from a month. After that period of time, the films were found to be difficult to handle, as they got decomposed. So, this films were environment friendly and biodegradable in nature.

\section{Effect of Radiation Dose in PVA-Gelatin-NCC Films}

Gamma radiation produced free radicals and ions which initiated the crosslinking among PVA-GelatinNCC. The cross-linking properties had significant changes with the physical and thermo-mechanical properties of the films. Due to radiation dose, the mechanical properties of PVA, PVA-Gelatin and PVAGelatin-NCC-based films were improved. The tensile strength of the films were increased to $14.5 \%, 11.9 \%$ and $22.7 \%$ respectively. The tensile modulus and elongation properties were significantly improved. The moisture content of the films were decreased for the addition of NCC into PVA-Gelatin film. The water uptake percentages were drastically decreased after radiation.

\section{CONCLUSION}

The fabrication of biodegradable film using PVA, gelatin and nano crystalline cellulose was done successfully. The addition of NCC showed drastic changes with its thermo-mechanical and physical properties. Spectroscopic analysis was also carried out using Fourier Transform Infra-Red Spectroscopy and crystallinity by X-Ray Diffraction process. The surface morphological changes were investigated by Scanning Electron Microscopy and a significant modification was observed due to addition of NCC. Degradation test was successfully supported by using soil media. The fabricated films showed excellent thermo-mechanical properties that are well suited to be used as packaging materials.

\section{REFERENCE}

[1] Khan MA, Khan RA, Zaman H, Hossain MA, Khan AH, Effect of gamma radiation on the physico-mechanical and electrical 
properties of jute fiber-reinforced polypropylene composites $\mathrm{J}$ Reinf Plast Compos 2009; 28: 1651.

https://doi.org/10.1177/0731684408090365

[2] Li C, Zhao Q, Deng H, Chen C, Wang K, Zhang Q, Chen F, $\mathrm{Fu} Q$. Preparation, structure and properties of thermoplastic olefin nanocomposites containing functionalized carbon nanotubes. Polym Int 2011; 60: 1629. https://doi.org/10.1002/pi.3141

[3] Poletto M, Ornaghi HL, Zattera A. Native cellulose: structure, characterization and thermal properties. J Materials 2014; 7(9): 6105-6119. https://doi.org/10.3390/ma7096105

[4] Meng F, Zhang Y, Xiong Z, Wang G, Li F, Zhang L. Mechanical, hydrophobic and thermal properties of an organic-inorganic hybrid carrageenan-polyvinyl alcohol composite film. Compos Part B-Eng 2018; 143: 1-8. https://doi.org/10.1016/j.compositesb.2017.12.009

[5] Shahbazi M, Rajabzadeh G, Rafe A, Ettelaie R, Ahmadi SJ. The physico-mechanical and structural characteristics of blend film of poly (vinyl alcohol) with biodegradable polymers as affected by disorder-to-order conformational transition. Food Hydrocoll 2016; 60: 393-404. https://doi.org/10.1016/j.foodhyd.2016.03.038

[6] Nakano Y, Bin Y, Bando M, Nakashima T, Okuno T, Kurosu $\mathrm{H}$, Matsuo. Structure and mechanical properties of chitosan/poly (vinyl alcohol) blend films. Macromol Symp 2007; 258(1): 63-81. https://doi.org/10.1002/masy.200751208

[7] Mohsin M, Hossin A, Haik Y. Thermal and mechanical properties of poly (vinyl alcohol) plasticized with glycerol. J Appl Polym Sci 2011; 122(5): 3102-3109. https://doi.org/10.1002/app.34229

[8] Ahmed T, Shahid M, Azeem F, Rasul I, Shah AA, Noman M, Hameed A, Manzoor N, Manzoor I, Muhammad S. Biodegradation of plastics: current scenario and future prospects for environmental safety. Environ Sci Pollut Res 2018; 25(8): 7287-7298.

https://doi.org/10.1007/s11356-018-1234-9

[9] Zaman HU, Khan MA, Khan RA, Improvement of physicomechanical, thermomechanical, thermal and degradation properties of PCL/gelatin biocomposites: Effect of gamma radiation. Open J Compos Mater 2012; 2(01): 15.
[10]

Jo C, Kang $\mathrm{H}$, Lee NY, Kwon JH, Byun MW. Pectin-and gelatin-based film: effect of gamma irradiation on the mechanical properties and biodegradation. Radiat Phys Chem 2005; 72(6): 745-750.

https://doi.org/10.1016/j.radphyschem.2004.05.045

[11] Kozlov PV, Burdygina GI. The structure and properties of solid gelatin and the principles of their modification. Polym 1983; 24(6): 651-666. https://doi.org/10.1016/0032-3861(83)90001-0

[12] Gul-E-Noor F, Khan MA, Ghoshal S, Mazid RA, Sarwaruddin Chowdhury AM, Khan RA. Grafting of 2-ethylhexyl acrylate with urea on to gelatin film by gamma radiation. $J$ Macromol Sci A 2009; 46(6): 615-624. https://doi.org/10.1080/10601320902851926

[13] Khan RA, Beck S, Dussault D, Salmieri S, Bouchard J, Lacroix M. Mechanical and barrier properties of nanocrystalline cellulose reinforced poly (caprolactone) composites: Effect of gamma radiation. J Appl Polym Sci 2013; 129(5): 3038-3046. https://doi.org/10.1002/app.38896

[14] Liu Y, Li L, Pan N, Wang Y, Ren X, Xie Z, Buschle-Diller G Huang TS. Antibacterial cellulose acetate films incorporated with $\mathrm{N}$-halamine-modified nano-crystalline cellulose particles. Polym Advan Technol 2017; 28(4): 463-469. https://doi.org/10.1002/pat.3906

[15] El Miri N, Aziz F, Aboulkas A, El Bouchti M, Ben Youcef H, El Achaby M. Effect of plasticizers on physicochemical properties of cellulose nanocrystals filled alginate bionanocomposite films. Advan Polym Technol 2018; 37(8): 3171-3185.

https://doi.org/10.1002/adv.22087

[16] Lam E, Male KB, Chong JH, Leung AC, Luong JH. Applications of functionalized and nanoparticle-modified nanocrystalline cellulose. Trends Biotechnol 2012; 30(5): 283-290. https://doi.org/10.1016/j.tibtech.2012.02.001

[17] Khan A, Huq T, Khan RA, Dussault D, Salmieri S, Lacroix M Effect of gamma radiation on the mechanical and barrier properties of HEMA grafted chitosan-based films. Radiat Phys Chem 2012; 81(8): 941-944. https://doi.org/10.1016/j.radphyschem.2011.11.056

[18] Bourtoom T. Edible protein films: properties enhancement. Int Food Res J 2009; 16(1): 1-9.

\section{DOI: https://doi.org/10.6000/1929-5995.2019.08.02}

(C) 2019 Karmaker et al.; Licensee Lifescience Global.

This is an open access article licensed under the terms of the Creative Commons Attribution Non-Commercial License (http://creativecommons.org/licenses/by-nc/3.0/) which permits unrestricted, non-commercial use, distribution and reproduction in any medium, provided the work is properly cited. 